\title{
Spontaneous intra-gastric rupture of walled-off pancreatic necrosis: Endoscopic ultrasound features
}

\author{
Surinder Singh Rana, Vishal Sharma, K. V. Raghavendra Prasad, Ravi Sharma, Puneet Chhabra, \\ Deepak Gunjan, Rajesh Guptaㅁ, Deepak Kumar Bhasin
}

Departments of Gastroenterology and 'Surgery, Post Graduate Institute of Medical Education and Research, Chandigarh, India

\begin{tabular}{l|l} 
Abstract & $\begin{array}{l}\text { Walled-off necrosis (WON) is a delayed local complication of acute pancreatitis. It is usually } \\
\text { associated with acute necrotizing pancreatitis. It requires drainage if it is infected, associated with } \\
\text { gastric or biliary obstruction or is painful. Asymptomatic WON are usually managed conservatively. } \\
\text { Occasionally, WON may spontaneously fistulize into gastrointestinal lumen or may rupture into } \\
\text { the peritoneum. We describe the endoscopic demonstration of a case of spontaneous rupture } \\
\text { of WON into the stomach and its subsequent uncomplicated resolution. Spontaneous rupture } \\
\text { of WON into gastrointestinal tract with uncomplicated resolution is a rare event. }\end{array}$ \\
Key words & $\begin{array}{l}\text { Acute pancreatitis, fistula, spontaneous rupture, walled-off necrosis } \\
\text { Kats }\end{array}$
\end{tabular}

\section{Introduction}

The revised Atlanta classification of acute pancreatitis (AP) has distinguished pancreatic pseudocysts from walled-off necrosis (WON) ${ }^{[1]}$ WON is an encapsulated collection of pancreatic or peripancreatic necrosis which has a well-defined wall and usually forms 4 weeks or later after the onset of AP. Spontaneous internal drainage of pseudocyst into gastrointestinal tract (GIT) has been reported in literature and is usually associated with bleeding complications that require immediate surgical or radiological intervention. However, spontaneous rupture of walled-off pancreatic necrosis (WOPN) into GIT is a rare event, and only few case reports have described it. ${ }^{[2,3]}$

\section{Case Report}

A 28-year-old male patient presented to us with a single episode of hematemesis. This was accompanied with

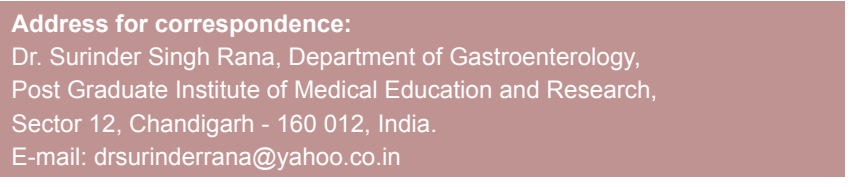

\begin{tabular}{|l|c|}
\hline \multicolumn{2}{|c|}{ Access this article online } \\
\hline \multirow{2}{*}{$\begin{array}{l}\text { Website: } \\
\text { www.jdeonline.in }\end{array}$} & Quick Response Code \\
\hline \multirow{2}{*}{$\begin{array}{l}\text { DOI: } \\
\text { 10.4103/0976-5042.195770 }\end{array}$} & \\
\hline
\end{tabular}

melena but not with postural symptoms. He was diagnosed as idiopathic acute necrotizing pancreatitis 3 months back and had developed an asymptomatic WON at tail end of pancreas. Ultrasound of abdomen done 3 weeks back had revealed $7 \mathrm{~cm}$ WOPN along with splenic vein thrombosis. On presentation, he had pulse rate of $96 / \mathrm{min}$ and blood pressure of $110 / 70 \mathrm{mmHg}$. His hemoglobin was $9.6 \mathrm{~g} \%$. Gastroscopy revealed a dark foreign body firmly adherent to the mucosa of the body of the stomach [Figure 1]. Fresh blood was seen at the base of this foreign body. A part of this foreign body protruding out from the mucosa was carefully removed using dormia basket and it had the appearance of necrotic material. Endoscopic ultrasound (EUS) revealed multiple perigastric collaterals [Figure 2; black arrows] and WOPN had considerably decreased is size [Figure 2; white arrows]. Close examination revealed WOPN breaching the gastric wall [Figure 3; white arrows]. A contrast-enhanced computed tomography of abdomen revealed similar findings [Figure 4; black arrows]. He was managed conservatively with intravenous proton pump inhibitors and antibiotics. He remained well and was discharged after 5 days.

This is an open access article distributed under the terms of the Creative Commons Attribution-NonCommercial-ShareAlike 3.0 License, which allows others to remix, tweak, and build upon the work non-commercially, as long as the author is credited and the new creations are licensed under the identical terms.

For reprints contact: reprints@medknow.com

How to cite this article: Rana SS, Sharma V, Raghavendra Prasad KV, Sharma R, Chhabra P, Gunjan D, et al. Spontaneous intra-gastric rupture of walled-off pancreatic necrosis: Endoscopic ultrasound features. J Dig Endosc 2016;7:160-2. 


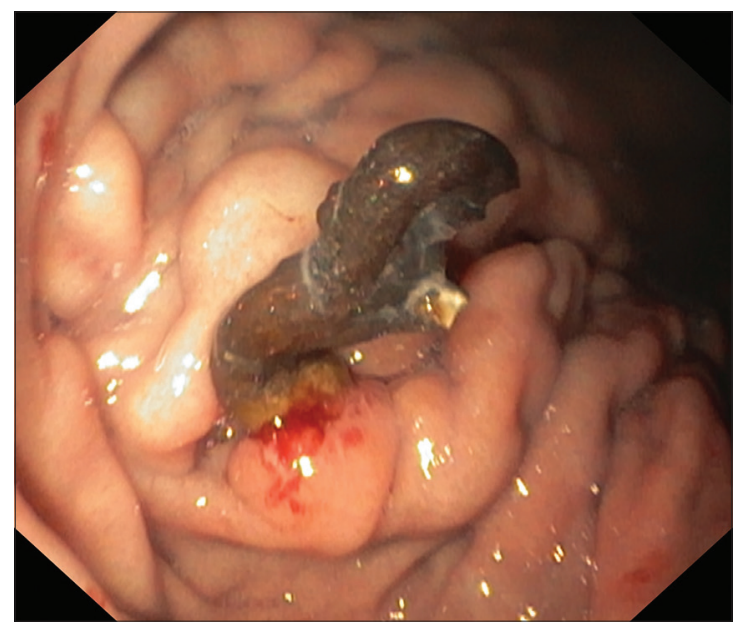

Figure 1: Endoscopy: Dark foreign body firmly adherent to the mucosa of the body of the stomach. Fresh blood seen at the base of this foreign body

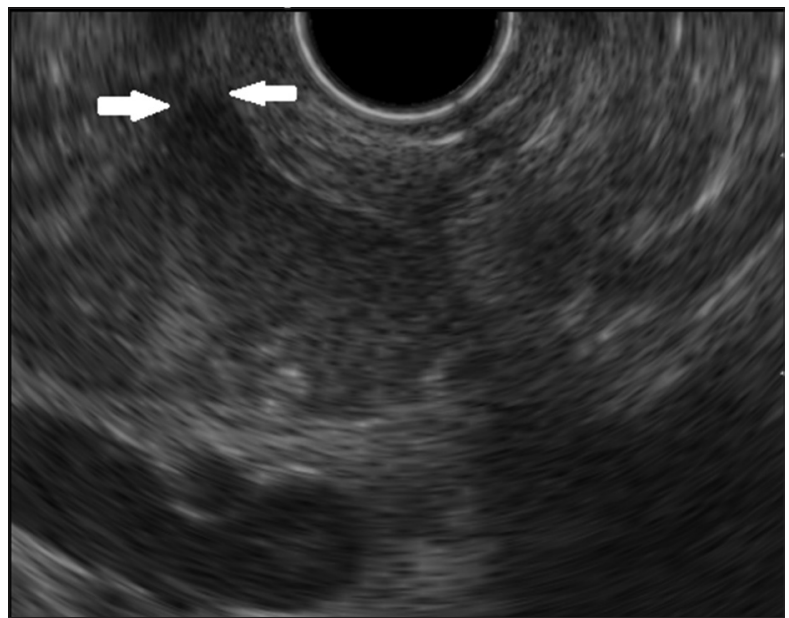

Figure 3: Endoscopic ultrasound: Walled-off pancreatic necrosis breaching the gastric wall (white arrows)

\section{Discussion}

Local complications of AP include acute peripancreatic fluid collection, acute necrotic collection, pseudocyst, and WON ${ }^{[1,4]}$ Conservative management is usually advocated in asymptomatic WON while drainage is required in cases of infected WON or when there is refractory abdominal pain, or failure to thrive or gastric or biliary obstruction. ${ }^{[1]}$

EUS is the diagnostic modality of choice for definitive characterization of pancreatic fluid collection and planning management. ${ }^{[5]}$ Morphological features of WON on initial EUS determine the number of endoscopic sessions required for endoscopic drainage, need for direct endoscopic necrosectomy or surgery. ${ }^{[6]}$ EUS has also been used to follow the patients of asymptomatic WON, and it has been shown that the solid component in WON tend to liquefy over time. ${ }^{[7]}$ However, the natural history of untreated WOPN

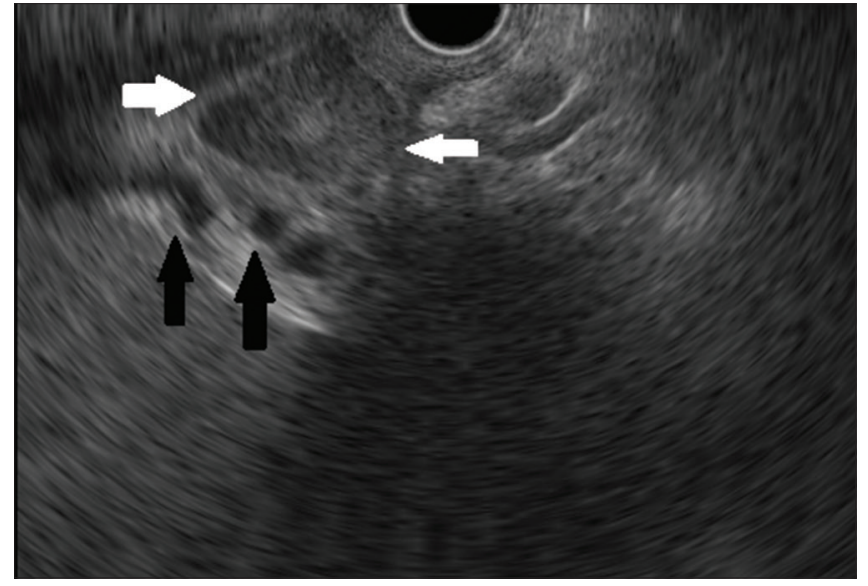

Figure 2: Endoscopic ultrasound: Multiple perigastric collaterals (black arrows) and walled-off pancreatic necrosis had considerably decreased is size (white arrows)

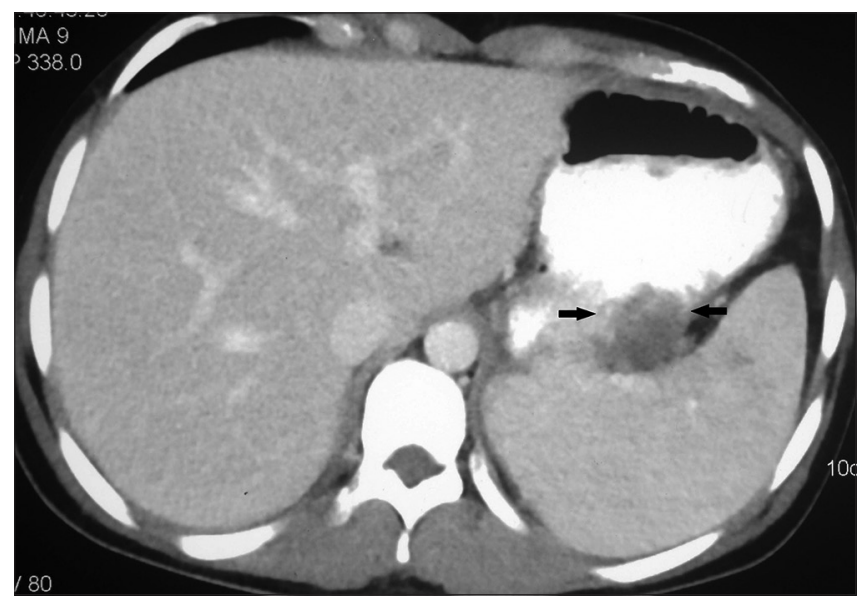

Figure 4: Contrast enhanced computed tomography: Walled-off pancreatic necrosis breaching the gastric wall (arrows)

is still not clear, but the majority of them seem to resolve spontaneously.

There are many case reports/series describing spontaneous rupture or fistulization of pseudocysts into adjacent structures such as stomach, duodenum, or colon resulting in either further complications or resolution of the condition. ${ }^{[8-10]}$ Location of the gastrointestinal fistula in the GIT might predict the outcome. Doberneck had reported closure of fistulas with conservative management in three fourth of duodenal fistula and one-third of jejunal fistula whereas all five colonic fistulas in their series required surgery. ${ }^{[11]}$ Thus, uncomplicated resolution of spontaneous fistulization of pseudocyst or WON is not common. In our case, with the rupture of WON into stomach, there was complete resolution of symptoms.

\section{Financial support and sponsorship} Nil. 


\section{Conflicts of interest}

There are no conflicts of interest.

\section{References}

1. Banks PA, Bollen TL, Dervenis C, Gooszen HG, Johnson CD, Sarr MG, et al. Classification of acute pancreatitis-2012: Revision of the Atlanta classification and definitions by international consensus. Gut 2013;62:102-11.

2. Papadimitriou N, Robotis J, Rokkas T. Spontaneous intra-gastric walled-off pancreatic necrosis rupture. JOP 2014;15:628-9.

3. Boopathy V, Balasubramanian P, Alexander T, Koshy R. Spontaneous fistulisation of infected walled-off necrosis (WON) into the duodenum in a patient following acute necrotising pancreatitis. BMJ Case Rep 2014;2014. pii: bcr2013202863.

4. Cui ML, Kim KH, Kim HG, Han J, Kim H, Cho KB, et al. Incidence, risk factors and clinical course of pancreatic fluid collections in acute pancreatitis. Dig Dis Sci 2014;59:1055-62.
5. Sharma V, Rana SS, Bhasin DK. Endoscopic ultrasound guided interventional procedures. World J Gastrointest Endosc 2015;7:628-42.

6. Rana SS, Bhasin DK, Sharma RK, Kathiresan J, Gupta R. Do the morphological features of walled off pancreatic necrosis on endoscopic ultrasound determine the outcome of endoscopic transmural drainage? Endosc Ultrasound 2014;3:118-22.

7. Rana SS, Bhasin DK, Reddy YR, Sharma V, Rao C, Sharma RK, et al. Morphological features of fluid collections on endoscopic ultrasound in acute necrotizing pancreatitis: do they change over time? Ann Gastroenterol 2014;27:258-61.

8. Clements JL Jr., Bradley EL $3^{\text {rd }}$, Eaton SB Jr. Spontaneous internal drainage of pancreatic pseudocysts. AJR Am J Roentgenol 1976;126:985-91.

9. Uiterwaal MT, Overbosch EH, Bruno MJ, van der Hulst RW. Spontaneous drainage of a pancreatic pseudocyst after embolization of a bleeding pseudoaneurysm. Cardiovasc Intervent Radiol 2009;32:192-4.

10. Mir MF, Shaheen F, Gojwari TA, Singh M, Nazir P, Ahmad S. Uncomplicated spontaneous rupture of the pancreatic pseudocyst into the gut - CT documentation: A series of two cases. Saudi J Gastroenterol 2009;15:135-6.

11. Doberneck RC. Intestinal fistula complicating necrotizing pancreatitis. Am J Surg 1989;158:581-3. 